\title{
EFEITO DA APLICAÇÃO DE DIFERENTES DOSES DE METOLACHLOR NO DESENVOLVIMENTO DO FEIJOEIRO COMUM (Phaseolus vulgaris L.)
}

\author{
Rogério FARINELli ${ }^{1,3,6}$, FERNANDO GUIDO PENARIOL ${ }^{1,3,6}$, ANGELA CRISTINA CAMARIM \\ Alvarez $^{1,3,6}$, SANDra Aparecida De SOUZA ${ }^{1,3,7}$, CAIO Vitagliano SANTI Rossi ${ }^{1,3}$, \\ MonicA Martins da Silva ${ }^{1,4,6}$, JoÃo DomingOS RodRIGUeS ${ }^{5}$ \\ ${ }^{1,3}$, Pós-Graduação/Mestrado Dept ${ }^{\circ}$ de Produção Vegetal - FCA/UNESP, Caixa Postal 237, CEP 18603- \\ 970, Botucatu, SP. E-mail: rfarinelli@fca.unesp.br \\ ${ }^{1,4}$ Pós-Graduação/Mestrado Dept ${ }^{\circ}$ de Engenharia Rural - FCA/UNESP, Caixa Postal 237, CEP 18603 - \\ 970, Botucatu, SP. \\ ${ }^{5}$ Dept $^{\circ}$ de Botânica - IB/UNESP, Caixa Postal 237, CEP 18603-970, Botucatu, SP. \\ ${ }^{6}$ Bolsistas CAPES \\ ${ }^{7}$ Bolsista CNPq
}

\begin{abstract}
RESUMO
No Brasil, a cultura de milho apresenta o maior consumo do herbicida metolachlor, porém com o aumento da área cultivada do feijão de inverno, esta cultura tornou-se um importante mercado para este produto. $\mathrm{O}$ trabalho foi desenvolvido na FCA/UNESP, Botucatu, SP, com o objetivo de avaliar os efeitos de diferentes doses do herbicida metolachlor no feijoeiro, utilizando o cultivar FT Bonito, no período "de inverno". Os tratamentos foram constituídos de cinco doses $(0 ; 1,0 ; 2,0 ; 3,0 ; 4,0$ e 5,0 $\mathrm{L} / \mathrm{ha}$ ) totalizando seis tratamentos com cinco repetições. O herbicida foi aplicado em pré-emergência, sendo realizadas nos estádios fenológicos V2, V3 e V4, correspondendo ao desdobramento de folhas primárias, emissão da primeira folha trifoliada e emissão da terceira folha trifoliada, as seguintes avaliações: altura de plantas; matéria seca da parte aérea e sintomas de fitotoxicidade. Verificou-se que, para a altura de plantas, no estádio V2 não foi verificada diferença significativa. No entanto, observou-se a ocorrência de sintomas de fitotoxicidade, que foram mais intensos no tratamento correspondente à maior dose do herbicida. Apesar da redução no desenvolvimento das plantas nos três estádios fenológicos não houve diminuição na produção de matéria seca.
\end{abstract}

PALAVRAS CHAVE: cloroacetamidas, herbicida, desenvolvimento.

\section{RATES OF METOLACHLOR IN COMMON BEAN (Phaseolus vulgaris L.) DEVELOPMENT ABSTRACT}

In Brazil, the maize crop presents the biggest consumption of metolachlor herbicide; however, with the increase of winter beans cultivated area, this culture became an important market for this product. The work was developed in FCA/UNESP, Botucatu, SP, with objective to evaluate rates of the metolachlor herbicide in the common bean, being used cultivar FT Bonito, in winter season. the development stadiums V2, V3 and V4. The treatments had been constituted of five doses $(0 ; 1,0$; 2,$0 ; 3,0 ; 4,0$ and $5,0 \mathrm{~L} / \mathrm{ha}$ ) totalizing 6 treatments with 5 repetitions. The herbicide was applied in pre-emergency, being carried through the following evaluations in the stadio V2, V3 and V4, corresponding to the unfolding of primary leaves, emission of 
the first trifoliate leaf and emission of the third trifoliate leaf: height of plants; dry matter of shoot and symptoms of toxicity. It was verified that in relation to the height of plants in the V2 stadium was not verified significant difference. However, it was observed the occurrence symptoms of toxicity, that were more intense in the biggest rate of herbicide. Despite the reduction in the development of the plants in three development stadiums it did not have reduction in the production of dry matter.

KEY WORDS: cloroacetamides, herbicide, development.

\section{INTRODUÇÃO}

O feijoeiro (Phaseolus vulgaris L.) possui pequena capacidade competitiva devido ao crescimento inicial lento e sistema radicular superficial, manifestando maior taxa de desenvolvimento apenas 18 a 22 dias após a emergência, ou seja, após a emissão da $3^{\mathrm{a}}$ folha trifoliada (Dourado Neto \& Fancelli, 2001).

Dessa forma, a cultura apresenta considerada sensibilidade à ocorrência de plantas daninhas, sendo a fase de maior susceptibilidade à interferência até os 30 dias após a emergência das plântulas (Almeida et al., 1983). De acordo com Moraes et al. (1987), a presença de plantas daninhas provoca prejuízos econômicos, por dificultar a operação de colheita, depreciar o produto colhido, abrigar insetos e microrganismos patogênicos e conseqüentemente diminuir a produtividade. Portanto, a utilização de um método efetivo de controle constitui prática indispensável para se obter maior produtividade e melhor qualidade do produto final.

O emprego de herbicidas para o controle de plantas daninhas é uma prática cultural usual, tendo crescimento considerável nas últimas décadas (Arruda et al., 1999). A escolha do produto e da dose deve estar relacionado diretamente com a máxima eficiência e eficácia do controle, uma vez que, tais produtos químicos podem elevar o custo de produção, provocar efeito fitotóxico, além de provocar contaminação ambiental.

Sendo assim, o conhecimento da seletividade do produto é de extrema importância para se ter confiança no momento de fazer a devida recomendação. Segundo Vellini et al (1992), a seletividade é caracterizada como sendo a capacidade de um determinado herbicida eliminar plantas daninhas que se encontram em uma cultura, sem reduzir a produtividade e a qualidade do produto final obtido. A sua determinação não pode ser apenas pela verificação ou não de sintoma de fitotoxicidade, pois já são conhecidos exemplos de herbicidas que podem reduzir a produtividade das culturas sem produzir efeitos visualmente detectáveis e também outros que provocam injúrias bastante acentuadas, mas que permitem às mesmas manifestar plenamente seus potenciais produtivos. Estas informações concordam com os estudos realizados por Lorenzi et al. (1994) onde se relatou que níveis significativos de injúrias não causaram redução de produtividade.

Dentre os herbicidas recomendados para a cultura do feijão, o metolachlor tem sido utilizado, principalmente em função de sua ação graminicida. Pertencente ao grupo químico dos cloroacetanilidos, atua sobre as plantas inibindo a germinação. Promotor de inibição da divisão celular, o produto paralisa o desenvolvimento das plantas daninhas, levando-as à morte antes ou logo após sua emergência (Hertwig, 1983).

Em virtude da absorção foliar desse herbicida ser quase nula, utiliza-se em préemergência das plantas daninhas, sendo a absorção pelo coleoptilo (gramíneas) e hipocótilo (dicotiledôneas) as principais formas. Na planta a translocação ocorre predominantemente via xilema, tendo atuação nas regiões meristemáticas, 
principalmente na região terminal do coleoptilo, onde provoca o rompimento das membranas celulares e inibe a divisão celular paralisando o crescimento das raízes e das plântulas. Dessa forma a aplicação deve ser realizada antes das sementes alcançarem um estado avançado de germinação (Rodrigues et al., 1995).

Hertwig (1983) cita que devido à alta seletividade do princípio ativo, o metolachlor não causa efeitos fitotóxicos em feijoeiro, desde que se empregue a dose recomendada. Segundo Procópio et al. (2001), a seletividade ao metolachlor pode estar relacionada a vários fatores como o solo, o clima, o manejo da irrigação e a dose do produto, entre outros. A dose aplicada é calculada em função da vazão, faixa de deposição e da velocidade de deslocamento da barra de pulverização (Saad, 1981). Desse modo, no momento da aplicação, a ocorrência de alguma variação em um desses três fatores pode alterar a quantidade de produto aplicada. Em condições de campo, é comum a ocorrência de sobreposição da faixa de deposição, aumentado a quantidade de produto nessa área, podendo acarretar danos à cultura.

O presente trabalho teve como objetivo avaliar os efeitos de diferentes doses do herbicida Metolachlor (Dual 960 CE) no feijoeiro, cv. FT Bonito, no período "de inverno", nos estádios fenológicos V2, V3 e V4, correspondendo ao desdobramento de folhas primárias, emissão da primeira folha trifoliada e emissão da terceira folha trifoliada.

\section{MATERIAL E MÉTODOS}

O experimento foi instalado em túnel de vegetação do Departamento de Produção Vegetal-Agricultura, na Fazenda Experimental Lageado da FCA, UNESP de Botucatu-SP.

Antes da instalação do experimento foi realizada a análise química do solo, de acordo com a metodologia de Raij (1987), cujo resultado está apresentado na Tabela 1.

Tabela 1. Características químicas do solo utilizado. Botucatu-SP.

\begin{tabular}{cccccccccc}
\hline $\mathrm{pH}$ & $\mathrm{M} . \mathrm{O}$. & $\mathrm{P}$ & $\mathrm{H}+\mathrm{Al}$ & $\mathrm{K}$ & $\mathrm{Ca}$ & $\mathrm{Mg}$ & $\mathrm{SB}$ & $\mathrm{CTC}$ & $\mathrm{V}$ \\
\hline$\left(\mathrm{CaCl}_{2}\right)$ & $\left(\mathrm{g} \cdot \mathrm{kg}^{-1}\right)$ & $\mathrm{mg} \cdot \mathrm{dm}^{-3}$ & & $--------------\mathrm{mmol}_{\mathrm{c} \cdot} \cdot \mathrm{dm}^{-3}$ & --------------- & $(\%)$ \\
\hline 5,31 & 27,4 & 31,2 & 31 & 1 & 43 & 17 & 60 & 91 & 66 \\
\hline
\end{tabular}

O solo foi colocado em vasos plásticos com capacidade de 8 litros, sendo posteriormente realizada a adubação de semeadura, utilizando-se 3 gramas por vaso do fertilizante granulado 4-14-8 com 0,5\% de Zn, segundo recomendação de Ambrosano et al. (1997).

A semeadura foi realizada manualmente no dia 4 de abril de 2002, utilizando cinco sementes por vaso do cultivar FT-Bonito (grupo Carioca, hábito de crescimento indeterminado, tipo II, ciclo 94 dias). Após sete dias da emergência, foi realizado o desbaste, permanecendo as duas plantas mais vigorosas de cada vaso.

A aplicação das doses do herbicida metolachlor foi realizada logo após a semeadura em condições de pré-emergência. No momento da aplicação, a temperatura do ar situava-se em torno de $28^{\circ} \mathrm{C}$ com umidade relativa de $55 \%$, sendo que a pulverização ocorreu no período das $16 \mathrm{~h} 30$ às $17 \mathrm{~h}$. Para a aplicação foi utilizado um pulverizador costal, pressurizado à $\mathrm{CO}_{2}$, com bicos tipo leque série XR 8004, calibrados com $2,0 \mathrm{~kg} / \mathrm{cm}^{2}$ de pressão e com vazão de 200 1/ha de calda.

O delineamento experimental adotado foi o de blocos casualizados, com seis tratamentos e cinco repetições, relacionados na Tabela 2. 
Tabela 2. Herbicida utilizado com as respectivas doses do produto comercial e do ingrediente ativo, relacionando os tratamentos empregados. Botucatu-SP.

\begin{tabular}{c|c|c|c}
\hline \multicolumn{2}{c|}{ Características do herbicida } & \multicolumn{2}{c}{ Tratamentos } \\
\hline $\begin{array}{c}\text { Produto comercial } \\
\text { (p.c.) }\end{array}$ & $\begin{array}{c}\text { Ingrediente ativo } \\
\text { (i.a.) }\end{array}$ & $\begin{array}{c}\text { Dose do p.c. } \\
\text { L.ha }^{-1}\end{array}$ & $\begin{array}{c}\text { Dose do i.a } \\
\text { g.ha }^{-1}\end{array}$ \\
\hline & & Testemunha $(0)$ & Testemunha (0) \\
& & 1 & 960 \\
Dual 960 CE & Metolachlor & 2 & 1920 \\
& & 3 & 2880 \\
& & 4 & 3840 \\
& & 5 & 4800 \\
\hline
\end{tabular}

A emergência das plântulas ocorreu em 9 de abril de 2002, aos 5 dias após a semeadura .

A cultura foi irrigada alternando intervalos de 3 a 4 dias, com uma lâmina de água de 13,0 $\mathrm{mm}$ por rega, o que corresponde em média a $3 \mathrm{~mm}$ diários por vaso, seguindo recomendação de Silveira \& Stone (1979), utilizando-se um regador manual.

Os tratos fitossanitários foram realizados aos 15 dias após a emergência (DAE), realizando-se uma aplicação de benomyl (250 g/ha i.a.) e deltamethrin (1,5 g/ha i.a.), visando o controle curativo de doenças fúngicas foliares e pragas, respectivamente.

As avaliações foram realizadas nos estádios de folhas primárias (7 DAE), emissão da primeira folha trifoliada (15 DAE) e emissão da terceira folha trifoliada (21 DAE).

Os parâmetros avaliados foram os seguintes: altura de plantas (determinada medindo-se, em centímetros, a distância desde o colo até a inserção da folha trifoliada mais desenvolvida); matéria seca da parte área (definida como sendo a fitomassa de toda a planta, em gramas, exceto raízes, depois de seca em estufa a $60^{\circ} \mathrm{C}$, com circulação de ar forçada). Em cada parcela, a matéria seca foi definida como a somatória da matéria seca das duas plantas do vaso; fitotoxicidade (avaliada aos 7 DAE, adotandose uma escala visual do IAPAR, citada por Pereira \& Bazoni, 1995, onde 0\% corresponde à ausência de injúria e $100 \%$ à dano total ou morte da planta.

Os resultados foram submetidos à análise de variância e as médias comparadas pelo teste de Tukey ao nível de significância de igual a 5\% de probabilidade.

\section{RESULTADOS E DISCUSSÃO}

Na Tabela 3 encontram-se os resultados obtidos para altura de plantas, fitotoxicidade e matéria seca final.

Tabela 3. Resultados da análise de variância para altura de plantas nos estádios de folhas primárias desenvolvidas, emissão da primeira folha trifoliada e emissão da terceira folha trifoliada, notas de fitotoxicidade e matéria seca final. Botucatu-SP.

\begin{tabular}{l|l|l|l}
\hline \multirow{2}{*}{ Tratamentos } & Altura de plantas $(\mathrm{cm})$ & Fitotoxicidade & Matéria seca
\end{tabular}




\begin{tabular}{c|ccc|c|c} 
(L/ha p.c.) & $\begin{array}{c}\text { Folhas } \\
\text { primárias }\end{array}$ & $\begin{array}{c}\text { Primeira } \\
\text { folha } \\
\text { trifoliada }\end{array}$ & $\begin{array}{c}\text { Terceira } \\
\text { folha } \\
\text { trifoliada }\end{array}$ & & \multirow{2}{*}{ (g/vaso) } \\
\hline Testemunha & $5,40 \mathrm{a}$ & $13,40 \mathrm{a}$ & $18,60 \mathrm{a}$ & $0,00 \mathrm{c}$ & $6,43 \mathrm{a}$ \\
1 & $5,30 \mathrm{a}$ & $12,90 \mathrm{ab}$ & $18,10 \mathrm{a}$ & $2,00 \mathrm{c}$ & $6,08 \mathrm{a}$ \\
2 & $5,05 \mathrm{a}$ & $12,75 \mathrm{ab}$ & $17,30 \mathrm{ab}$ & $6,00 \mathrm{~b}$ & $6,21 \mathrm{a}$ \\
3 & $4,65 \mathrm{a}$ & $12,25 \mathrm{ab}$ & $16,10 \mathrm{abc}$ & $8,00 \mathrm{~b}$ & $5,92 \mathrm{a}$ \\
4 & $4,20 \mathrm{a}$ & $11,60 \mathrm{ab}$ & $15,30 \mathrm{bc}$ & $10,0 \mathrm{~b}$ & $6,07 \mathrm{a}$ \\
5 & $4,05 \mathrm{a}$ & $10,80 \mathrm{~b}$ & $14,25 \mathrm{c}$ & $29,0 \mathrm{a}$ & $5,77 \mathrm{a}$ \\
\hline Média geral & 4,77 & 12,28 & 16,60 & 9,16 & 6,08 \\
CV \% & 15,12 & 10,10 & 7,85 & 39,83 & 10,30 \\
Teste F & $3,10^{\mathrm{ns}}$ & $2,93^{*}$ & $8,36^{* *}$ & $40,56^{* *}$ & $0,67^{\mathrm{NS}}$ \\
\hline
\end{tabular}

Obs.:

\footnotetext{
** = significativo à $1 \%$ de probabilidade;

$*$ = significativo à $5 \%$ de probabilidade;

${ }^{\mathrm{ns}}=$ não significativo à $5 \%$ de probabilidade;

$\mathrm{CV} .=$ coeficiente de variação.
}

Notas de fitotoxicidade foram transformadas para $\sqrt{x+0,5}$

Em relação à altura de plantas no estádio de folhas primárias (V2), não foi verificada diferença significativa. No entanto, observou-se que houve variação entre os tratamentos para as notas de fitotoxicidade, sendo que no tratamento correspondente à maior dose foi observada maior sintoma visual. Esse sintoma teve como características o enrugamento foliar, folhas em formato de "concha" e com aspecto retorcido, semelhantes ao observado por Fuerst \& Gronwald (1986). Porém o resultado obtido nessa avaliação está abaixo do aceitável, que segundo Pereira \& Bazoni (1995) situa-se em torno de $30 \%$ de toxicidade.

Não se observou sintomas de fitotoxicidade nos estádios de primeira e terceira folha trifoliada. No entanto, houve efeito das doses do metolachlor reduzindo a altura de plantas, em relação à testemunha que apresentou maiores valores, sendo que a dose de $5,01 /$ ha resultou em valor de altura de $10,80 \mathrm{~cm}$ para o estádio de primeira folha trifoliada e 14,25 cm para o estádio de terceira folha trifoliada. Resultado semelhante foi obtido por Procópio et al. (2001), que verificou que os valores de altura de plantas de feijão, cultivar Pérola, foram reduzidos em virtude de acréscimo de doses do mesmo herbicida. Contudo, a redução constatada no presente experimento durante o desenvolvimento da terceira folha trifoliada não interferiu significativamente na produção de matéria seca (Tabela 3), concordando apenas com o resultado de Vellini (1992), uma vez que Procópio et al. (2001) obteve redução de matéria seca da parte aérea, sendo que na dose de $4,80 \mathrm{~kg} / \mathrm{ha}$ a produção foi inferior a testemunha.

Esses resultados podem ser explicados provavelmente pelo modo de ação do herbicida, o qual é absorvido pela planta durante a emergência e transportado via xilema, concentrando-se inicialmente nas folhas primárias, onde foi observado sintomas visuais de fitotoxicidade. Como a absorção pelas raízes e o transporte pelo floema é quase nulo, o produto provavelmente não foi translocado até as partes mais desenvolvidas da planta. Com a provável metabolização do produto pela planta, não houve prejuízos na produção final de matéria seca, mesmo em doses acima do 
recomendado, que corresponde a 2,0 a 2,5 L/ha.. Klimont (1996) cita que características relacionadas às sementes das culturas, como o tamanho, também podem influenciar na tolerância ao metolachlor, todavia são pouco estudadas. Neste aspecto Silva et al. (1981) argumentam que sementes de peneira de tamanho 13 a 15 podem dar origem a plantas com maior reserva para a metabolização do produto em questão. Também salientam que para o efeito encontrado em relação à altura de plantas, o maior teor de reservas nutritivas nas sementes maiores pode ser o principal atenuador dos danos causados pelo metolachlor.

\section{CONCLUSÃO}

O metolachlor acarretou prejuízos no desenvolvimento inicial da cultura do feijão, proporcionando uma maior fitotoxicidade com a dose de $5 \mathrm{~L} / \mathrm{ha}$;

Nos estádios fenológicos de primeira folha e terceira folha trifoliada a redução da altura de plantas ocorreu devido o aumento das doses;

O metolachlor mesmo causando problemas no desenvolvimento inicial da cultura, aliado a uma maior fitotoxicidade com a dose de $5 \mathrm{~L} / \mathrm{ha}$, o dobro da recomendada, não afetou a produção de matéria seca aos 28 dias após a emergência.

\section{LITERATURA CITADA}

ALMEIDA, F.S.; RODRIGUES, B.N.; OLIVEIRA, V.F.I. Controle de plantas daninhas na cultura do feijão no Estado do Paraná. Londrina, IAPAR, 1983. 22p. (IAPAR. Circular, 32).

AMBROSANO, E.J.; TANAKA, R.T.; MASCARENHAS,A.A.; RAIJ, B.van; QUAGGIO, J.A.; CANTARELLA, H. Feijão. In: RAIJ, B. van; CANTARELA, H.; QUAGGIO, J.A.; FURLANI, A.M.C. Recomendações de adubação e calagem para o Estado de São Paulo. 2aed. Campinas: IAC, p. 189-195, 1997 (Boletim Técnico 100).

ARRUDA, J.S.; LOPES, N.F.; BACARIN, M.A. Crescimento de plantas de soja (Glycine Max L. MERR) em função de doses de sulfentrazone. Revista Brasileira de Fisiologia Vegetal. Londrina, v.11 (supl.), p.46, 1999.

DOURADO NETO, D.; FANCELLI, A.L. Manejo de plantas daninhas. In: DOURADO NETO, D.; FANCELLI, A.L. Produção de feijão. Guaíba: Ed. Agropecuária, 2001. cap 5., p.175-176.

FUERST, E.P.; GRONWALD, J.W. Induction of rapid metabolism of metolachlor in sorghum shoots by CGA-92194 and other antidotes. Weed Science. Ithaca, v.34, p.354361, 1986.

HERTWIG, K.V. Manual de herbicidas, desfolhantes, dessecantes, fitorreguladores e bioestimulantes. São Paulo: Agronômica Ceres, 1983. p.120-125.

KLIMONT, K. The effect of herbicides on soybean seed quality. Biuletyn Instytutu Hodowli Aklimatyzacji. n.198, p.127-132, 1996.

LORENZI, H.J.; BRUNELLI NETO, V.; OLIVEIRA, J.E. Estudo do efeito do herbicida oxifluorfen, aplicado em pré-emergência, sobre o crescimento e produtividade 
da cana-de-açúcar (Saccharum officinarum) cv. SP 71-6163. STAB, Piracicaba, v.12, n.4, p.25-26, 1994.

MORAES, D.M. et al. Efeito de metribuzin sobre a qualidade fisiológica de sementes de soja. Revista Brasileira de Sementes. Campinas, v.19, n.2, p.160-164, 1987.

PEREIRA, F.A.R.; BAZONI, R. Avaliação de herbicidas na cultura da soja em áreas de cerrado de Mato Grosso do Sul. Campo Grande. MS. EMPAER, 1995, 38p. (EMPAER, MS. Documento 45).

PROCÓPIO, S.O. de.; SILVA, A.A. da.; SANTOS, J.B. dos.; ARAÚJO, E.F.; JÚNIOR, J.I.R.; FERREIRA, L.R. Revista Brasileira de Herbicidas. Brasília, v.2, n.3, p.133$141,2001$.

RODRIGUES, B. N.; ALMEIDA, F.S. de (ed). Guia de herbicidas. 3 ed. Londrina, 1995. 675p.

SAAD, O. Calibragem e cálculos de dosagem. In: SAAD, O. A vez dos herbicidas. São Paulo: Nobel, 1981. cap.5, 2 ed., p.143-164.

SILVA, J.F.; SILVA, J.F.; SILVA, R.F.; CONDÉ, A.R. Tolerância do tamanho da semente de soja (Glycine max L. Merr). ao metribuzin. Planta Daninha. Viçosa, v.4. p.92-96, 1981.

SILVEIRA, P.M. da; STONE, L.F. Balanço de água na cultura do feijão em Latossolo Vermelho-Amarelo. Pesquisa Agropecuária Brasileira. Brasília, v.14(2), p.111-115, 1979.

VELLINI, E.D.; FREDERICO, L.A.M.; MORELLI, J.L.; MARUBAUYASA, O.M. Avaliação dos efeitos do herbicida clomazoni, aplicado em pós-ermergência inicial, sobre o crescimento e produtividade de soqueira de cana-de-açúcar (Saccharum offcinarum) cv. SP 71-1406. STAB, Piracicaba, v.10, n.4, p.13-16, 1992. 